\title{
Innovative projects and programmes for the strategic development of the municipality
}

\author{
Galina Semenova ${ }^{1,2, *}$ \\ ${ }^{1}$ Plekhanov Russian University of Economics, Stremyanny lane 36, Moscow, 117997, Russia \\ ${ }^{2}$ Moscow Region State University, Radio str, 10A, office 86, Moscow, 105005 Russia
}

\begin{abstract}
The relevance of the matter is caused by the fact that the essence of strategic planning consists in the definition of the priority sphere of social-and-economic development of the city district taking into account the external environment factors and available resources. It is necessary to prove the organization of the chosen project or programme, including sources and mechanisms of resources attraction, applied technologies, technical means, etc. within strategic management. The main document in the sphere of complex social-and-economic development of the municipal unit is the strategic plan that allows formulating the perspective purposes of the development, choosing alternative options of the municipality, thereby attracting investments into the projects and programmes. The subject of the research is the "City district Podolsk". Some problems of strategic planning of investment projects and programmes, which are necessary for the improvement of activity of the "city district Podolsk", are studied. The objective of the research is to develop recommendations on the strategic planning of activity of the "City district Podolsk". Calculations for three investment programmes are made for the identification of the most successful direction of strategic development of the "City district Podolsk" by the means of formulas of the indicator of efficiency and coefficient of competitiveness. The achieved results can be used for creation of the Draft of the strategic development plan for the "City district Podolsk" till 2022.
\end{abstract}

\section{Introduction}

Transition to the innovative technologies, deep modernization of not only the branches of economy, but also of the control system in general is the key to success in Russia as a whole, and in Moscow region in the foreseeable future. The municipality "City district Podolsk" is one of the largest industrial centers of Moscow region with diversified production and developed social infrastructure, founded in 1781.

The Moscow Railway (Kursk direction), which is the component of the transport-andcommunication framework of Moscow region and the central region in general, runs across the territory of "City district Podolsk". The city and its industrial enterprises are served by the railway stations Podolsk, Silicate and Kutuzovsky located on the main railroad

* Corresponding author: Sg6457@mail.ru, angela-1309.m@yandex.ru 
Moscow-Kharkiv in $40 \mathrm{~km}$ from Moscow. The basis of the economic-and-social development of "City district Podolsk" is made by the industrial production. The industrial enterprises are the main taxpayers of taxes in the budget of the city district. Development of the industry promotes the improvement of the quality of the citizens's life as it provides the employment of the population and high level of their salary.

The municipality "City district Podolsk" has considerable investment potential. The essential role for the investment attractiveness is played by the proximity to Moscow, high educational, professional and cultural level of the population. As the result of collaboration of local government bodies and business, the investment activity grows in "City district Podolsk". The area of "City district Podolsk" is 4039 hectares, including: 4030.7 hectares of settlements; 8.3 hectares of forest land. The population of the city was 302,831 persons (on 01.01.2018). Small and medium business also takes the important place in the economy of the city district and plays a significant role in the solution of economic-and-social tasks, as it promotes the creation of new jobs, saturation of the consumer market goods and services, contributes to fiscal charges to the city budget.

The implementation of programmes of complex social-and-economic development of the municipality "City district Podolsk" till 2022 will create the positive dynamics of the development of the general state of the citizens' health and the social status of the city, will allow increasing the coefficient of competitiveness of the city on production of consumer goods and freight and passenger turnover, thereby it will create the increase in the receipts of fiscal charges to the city budget. This article is devoted to the analysis of such programmes.

\section{Methodology}

There are own developments of techniques of the assessment of social-and-economic strategic projects and programmes in the Russian Federation. Today it is possible to allocate several groups of approaches to the assessment of the city strategy. Techniques of the assessment of the strategy are developed by the scientific community by the request of local government bodies, public authorities or on own initiative, as the methodological gap is felt. Municipalities can develop original techniques. The regional authorities are engaged in the development of techniques of assessment, creating the methodical recommendations that allow estimating strategic plans of the municipalities.

Among the techniques developed by scientific community, the special attention is paid to techniques of Closed Joint Stock Company "International Centre for Social and Economic Research "Leontief Centre" (CJSC ICSER "Leontief Centre") and Institute of City Economy Fund. Both techniques present complex projects for the estimates of city strategy. However, methods of the statistical analysis and expert assessment forming their basis are already proved.

The technique developed by CJSC ICSER "Leontief Centre" (B.S. Zhikharevich, N.B. Zhunda, I.A. Korelina, L.E. Limonov, O.V. Rusetskaya) formed the basis of monitoring of the Strategic plan of St. Petersburg for 2018-2020 [4].

The technique introduced in the practice of the Russian strategic planning by Institute of City Economy Fund (G.Yu. Vetrov, D.V. Vizgalov, D.V. Shanin, N.I. Sheverova) pays special attention to the assessment of medium-term and long-term programmes of socialand-economic development of municipal units. The key components of these techniques are the statistical analysis of data on the territories' social-and-economic development and expert assessment of programme and investment strategic projects [1]. At the same time, the complex of the problems existing at the level of municipal statistics does not allow fully tracing the extent of change of indicators necessary for the assessment. Thus, according to the Presidential decree "On the assessment of the efficiency of activity of local government 
bodies of city districts and municipal districts", it is offered to administrations of municipal units to collect and publish the statistical data used for calculation of indicators of activity of local government body on their official sites [2]. The technique of the use of expert estimates is also extended for the assessment of the activity of the authorities. However, the method of the expert analysis demands greater expenses, in comparison with the method of the statistical analysis, as the expert's work is the creative activity assuming the high level of competence of the expert, his or her knowledge of a concrete city situation, ability to place the priorities of social-and-economic development of the concrete territory properly.

Though the analyzed techniques have some common features, they seriously differ according to the internal contents. So, the technique of the "Leontief Centre" focuses on the substantial assessment of the strategy, and the technique of "Institute of city economy" Fund focuses on the institutional component [3].

It is possible to distinguish the criteria, which belong to the substantial part (process components, purposes and indicators of the assessment) and the nominal criteria (novelty, instrumentality, availability of statement, cost intensity). In the substantial part, both techniques supplement each other and show importance of advance of estimated components in methodology of city strategic planning. As for external, rating data, they show the difference of the approaches to the strategy assessment. So, having high degree of scientific novelty, both approaches differ in the choice of methodical approach to the assessment. The "Institute of city economy" Fund used the technique based on statistical data, whereas the "Leontief Centre" suggests to be based on the expert assessment. On the one hand, the strategy assessment through statistics is obvious, municipal authorities are regularly prepared and publish statistical data. Thus, it is possible to track the achievement of these or those indicators. But according to the authors, such approach attracts narrowmindedness of the assessment since it does not explain the reasons which promote or prevent these or those indicators [4]. However, such way of assessment is the least expensive for the city authorities.

The assessment of the strategy occurs as the assessment of three of its components [5]: city economic-and-social situation assessment; assessment of the implementation of the plan and the efficiency of the implementation of long-term target programmes; sociological assessment of realization of the strategy.

At the same time, the assessment of the strategy is carried out on the basis of indicators of the monitoring, developed with the use of quantitative indices. The implementation of monitoring at three levels is supposed, own subsystem (group) of indicators was developed for each of the levels, namely [6]: target reference points of the perspective image of the city till 2022; indicators of the tasks' realization within the strategic plan; indicators of the assessment of the efficiency of long-term target programmes.

The first group includes 14 indicators (target reference points) divided into three subgroups answering three strategic objectives of the Strategy (high quality standards of the urban environment, strong competitive economy and the city as the equal partner of the development). The second group was made by 52 indicators tied to the matters of the Strategy. The third group was formed according to the purposes and tasks of the long-term target programmes. The system of indicators was developed with the support of traditional principles: complexity, continuity, transparency, and comparability to retrospective indicators across Ryazan, Ryazan region, Russia in general, and other municipalities [7, 8]. Basic values for the initial year of the beginning of strategizing (2018) and target values for the final year of the realization of the Strategy (for indicators of the first and second groups) and for every year of the implementation of the appropriate target programme (for indicators of the third group) were set. 
Besides, for each of indicators of the second group, which are the key indicators for the Strategy monitoring, the calculation procedure on the basis of primary data with the indication of sources of these data was offered.

The approaches to the realization of the strategies' assessment were developed on the basis of indicators of monitoring. According to the principles of monitoring, three types of assessment were offered: city economic-and-social situation assessment, assessment of the of implementation of the plan and the efficiency of the implementation of long-term target programmes, and sociological assessment of the strategy realization [9]. Thus, it is possible to allocate the general trends of the Russian regional strategizing. First, the development of city and regional strategies is trusted to the consulting companies, at the same time, there is a danger that the invited experts will not be able to understand some specific features of the concrete municipal unit in details. Secondly, the strategic plans of the Russian cities are often simple in judgments, demonstrate no accurate, verified image of the desirable future. Thirdly, the strategic development plans of the Russian cities often do not contain any mechanisms of inclusion of the strategy in real social-and-economic structure of the concrete city, being just the project, which is torn off from the reality [10].

\section{Results}

Great investments are made into the strategic programmes and projects of the municipal unit, such as [5]:

- production of the high-quality equipment for heating and nuclear energy industry, petrochemical and gas industry of goods at the regional level;

- high-quality production of light manufacturing in the scales of Moscow region;

- improvement and expansion of transport infrastructure, construction of high-speed highways.

The author offered the following priority directions for the investments [11]:

1. "Podolsk is the Centre of Sports Tourism" programme.

2. "Podolsk is the Transport Hub of the Central Region" programme.

3. "Podolsk is the Industrial Centre of the Moscow Region" programme.

Let us consider three of these programmes in more detail.

Programme 1. "Podolsk is the center of sports tourism".

Nowadays, the development of physical culture and sport in the country is carried out from the position of improvement of quality of life of the population, their welfare, formation of a healthy lifestyle, spirituality, civic consciousness and social activity of the Russians. The programme purpose is the improvement of the city image, the city equipment as the sports ground for holding tournaments and trainings, sport populization in society of the city. Investments into this programme are necessary for the creation of optimal conditions for visitors of athletes and tourists, increase in the quantity of platforms for trainings and the equipment of hotel complexes, promotion of a healthy lifestyle, etc.

Programme 2. "Podolsk is the transport hub of the central region".

The advantageous geographical location of the city fully allows using internal resources for the creation of modern transport and logistic hub, which will contribute to the development of growing volumes of foreign trade and strengthen the role of the city in the economic role of the region. The programme purpose is the creation of the conditions for formation in the municipal unit "City district Podolsk" of large transport and logistic hub that will give the chance to be integrated into the country transport and logistics system. Investments into this programme will help to create the control system of the transport and trade logistic complex, expansion and increase in number of transport and logistic platforms, warehouse and the equipment of modern container terminal complexes carrying 
out freight and passenger traffics, the increase in the freight and passenger traffics at the interregional and regional levels.

Programme 3. "Podolsk is the industrial center of the Moscow region".

The leading role in the social-and-economic development of the municipality "City district Podolsk" traditionally belongs to the industrial complex, making up about $25 \%$ in the structure of volumes of the shipped goods of own production [12]. 49 large and medium-sized industrial enterprises, more than 100 small and about 80 microenterprises carry out their activity in the territory of the city. These enterprises produce: the equipment for heating and nuclear energy industry, petrochemical and gas industry, cables, enameled wires, wiring products, cement, refractory materials, sewing and knitted products, products of food and processing industry, pharmaceutical, cosmetic products, kitchen and office furniture, construction materials, single-layer and corrugated fiberboard, filters of water treatment and water purification, children's tabletop games, mosaic puzzle, and many other things. The programme purpose is the development of "City district Podolsk" as the center of dynamic production of modern competitive consumer goods for the fullest satisfaction of needs of the population. Investments into this programme will give the increase in the production and selling of competitive consumer local products on the city and regional markets; development of production cooperation. It is directed to strengthening interaction of production spheres; carrying out technological modernization of production (technological modernization of the enterprises); development of infrastructure of consumer goods of local production, increase in the level of its innovation and quality providing.

We use the analysis of the existing data for the identification of the most successful direction of the strategic development of the municipality "City district Podolsk" and we will predict the effect of the introduction of each of the directions by the means of formulas of the indicator of the efficiency and the coefficient of competitiveness [13]:

$$
\varepsilon=\mathrm{N} * \Sigma\left|y i-y^{\prime} i\right| / \text { yi } * 100 \%
$$

where,

$\varepsilon$ - predicted indicators, efficiency indicator;

$\mathrm{N}$ - desirable time for which we predict;

yi - existing data;

$y^{\prime} i$ - estimated expenses.

where,

$$
\operatorname{Imn}=\varepsilon \times \mathrm{Li} / \mathrm{n}
$$

Imn - competitiveness coefficient;

$\varepsilon$ - performance indicator;

$\mathrm{Li}$ - target indicators of the development of the competition for the period;

$\mathrm{n}$ - period of time.

Let us calculate the efficiency indicator and the coefficient of competitiveness for these three programmes.

1. As the period of validity of the implementation of "Podolsk is the Centre of Sports Tourism" programme is 5 years, and as we use the basic data from the Programme of complex social-and-economic development of the municipality "City district Podolsk", we have [5]:

$$
\varepsilon=5 * \Sigma|460-2.036| / 460 * 100 \%=6.7 \%
$$

Apparently, the efficiency of the city activity will increase by $6.7 \%$.

Let us calculate the competitiveness coefficient, after introduction of this programme.

$$
\operatorname{Imn}=6.7 * 5.9 / 5=7.9
$$


2. "Podolsk is the Transport Hub of the Central Region" programme, its indicator of efficiency:

$$
\varepsilon=5 * \Sigma|578.6-1.17| / 578.6 * 100 \%=6.7 \%
$$

The coefficient of competitiveness:

$$
\operatorname{Imn}=6.7 * 6.5 / 5=8.7
$$

3. "Podolsk is the Industrial Centre of the Moscow Region" programme, its indicator of the efficiency:

$$
\varepsilon=5 * \Sigma|873.8-1.14| / 873.8 * 100 \%=6.9 \%
$$

The coefficient of competitiveness:

$$
\operatorname{Imn}=6.9 * 7.75 / 5=10.7
$$

We will present the obtained data in the form of charts for illustration purposes.

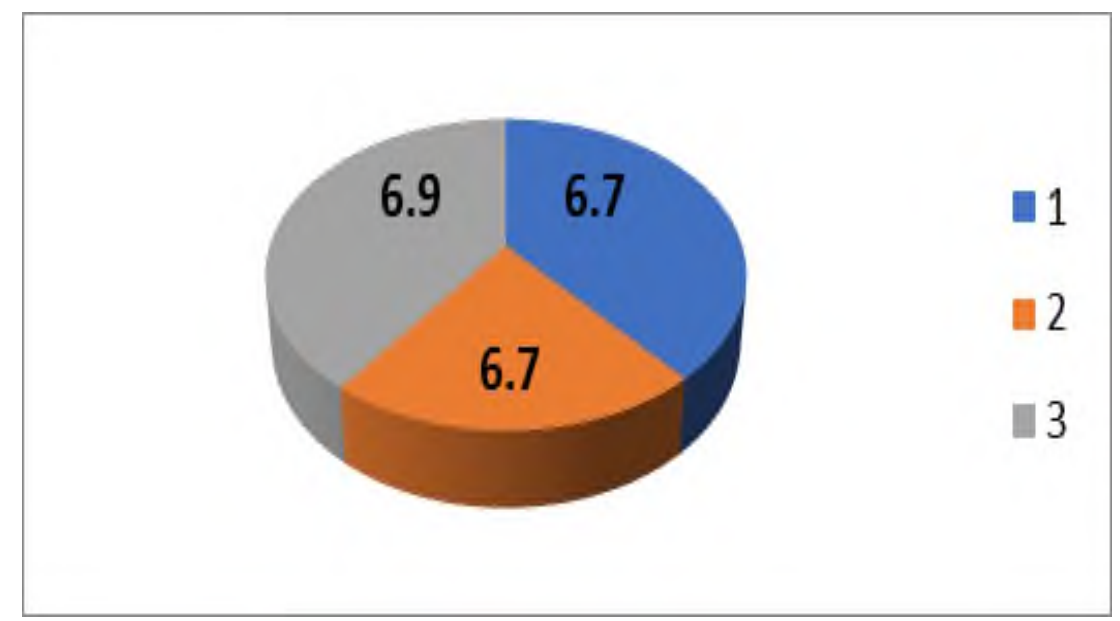

Fig. 1. Diagram of the indicator of the efficiency of the strategic programmes 1,2,3

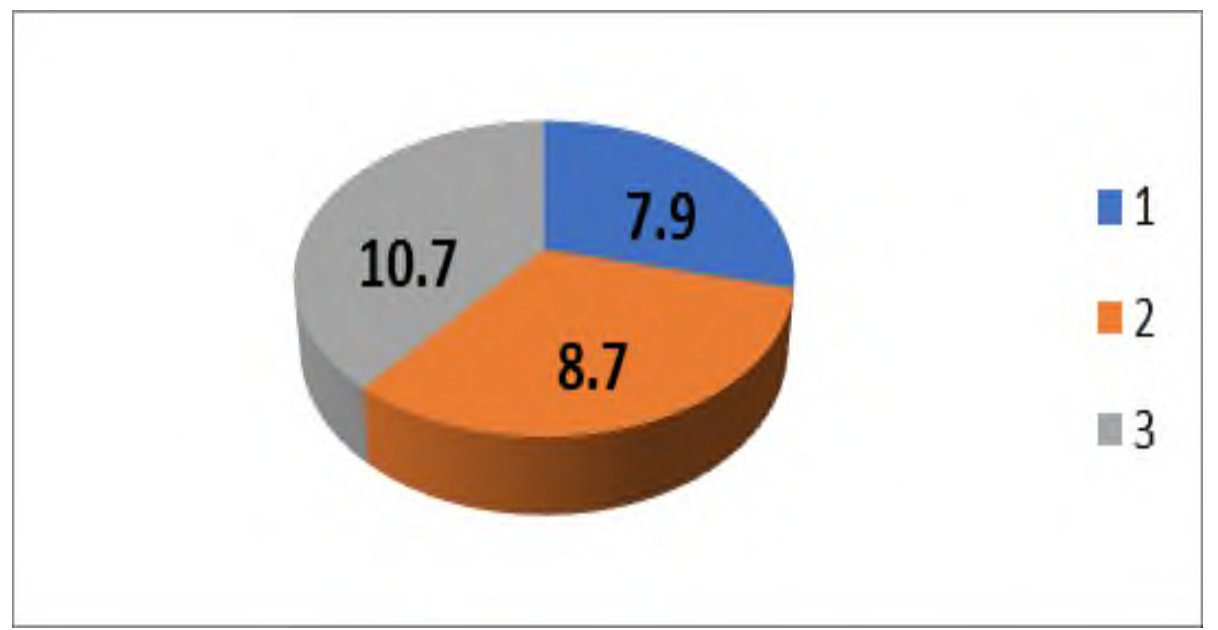

Fig. 2. Diagram of the coefficient of competitiveness of the strategic programmes 1, 2, 3 
After the analysis of the obtained data, it is possible to draw the proper conclusions.

The efficiency of the implementation of the strategic programme "Podolsk is the Centre of Sports Tourism" will be $6.7 \%$ (fig. 1), the coefficient of competitiveness will increase from 5.9 to 7.9 (fig. 2); after promotion of sport, it will allow an increase in the quantity of people, people engaged in physical education and sports in the city, which will create some positive dynamics of the development of the general state of the citizens health as well as the social status of the city.

First of all, "Podolsk is the Transport Hub of the Central Region" programme is aimed at the development and improvement of the road and transport system. The implementation of this programme will allow increasing freight and passenger turnover in the city and nominating it to the leading positions according to the indicators in the region. It will allow improving the coefficient of competitiveness of the city from 6.5 to 8.7 (fig. 2).

The results of the "Podolsk is the Industrial Centre of the Moscow Region" programme will allow increasing the coefficient of competitiveness of the city according to the production of consumer goods from 7.75 to 10.7 (fig. 2). Having acquired the status of the industrial centre, the municipality "City district Podolsk" will be able to take the leading positions according to the production of consumer goods in the regional scale.

Having carried out this research, we find it obvious which field of activity the local authorities should pay attention to in order to promote the "City district Podolsk" to a new, more perfect level [14]. As the calculations showed, the most effective programme is "Podolsk is the Industrial Centre of the Moscow Region" programme. Thus, the programme and target approach is one of the tools of the control system of the development of the municipality "City district Podolsk", the means of the implementation of social-andeconomic policy by the local authorities, the mechanism of impact on the economic processes within powers for the purpose of the formation of the conditions, providing consecutive improvement of quality of the population life in the city, effective and target use of budget funds.

\section{Conclusions}

Implementation of the three programmes will create some positive dynamics of the development of the municipality "City district Podolsk", namely: promoting and improving competitiveness of the city not only in the territory of Russia but also beyond its limits; the development and improvement of various allied industries; the improvement of quality of physical training of the population; the creation of the competitive transport and logistic centre at the means of the implementation of modern technologies, the increase in the quantity of transport and logistic platforms, the increase in the freight and passenger traffic, integration of "City district Podolsk" into the regional and interregional transport system; ensuring high rates and growth in volumes of the release of consumer goods of local production; growth of the share of competitive local products; the increase in the utilization of the capacity of the enterprises for release of consumer goods; the increase in the product range.

Such programmes will attract the additional income (taxes and collecting) in the budget of "City district Podolsk". 


\section{References}

1. K. Raczkowski, Public Management Theory and Practice (New York, Springer International Publishing, 2016)

2. C. Brooks, Introductory Econometrics for Finance, (2019) DOI: $10.1017 / 9781108524872$

3. A. M. Zaretskii, International Journal of Civil Engineering and Technology, 9(11), 1700-1708 (2018)

4. D. Radushinsky, A. Mottaeva, L. Andreeva, G. Dyakova, IOP Conf. Series: Earth and Environmental Science, 90, 012137 (2017) doi :10.1088/17551315/90/1/012218

5. A. Mottaeva, A. Minullina, IOP Conf. Series: Earth and Environmental Science, 90, 012123 (2017) doi :10.1088/1755-1315/90/1/012120

6. F. Scorza, B. Murgante, F. Amato, G. Botonico, International Journal of Electronic Governance, 11(1), 1 (2019) DOI: 10.1504/IJEG.2019.10018374

7. E. Akhmetshin, J. Muelleret al., Journal of Entrepreneurship Education, 21(1) (2019)

8. A. Mottaeva, E. Vasilyeva, MATEC Web of Conferences, 239, 04019 (2018) doi.org/10.1051/matecconf/201823904019

9. M. Görgüner, M. L. Deas, World Environmental and Water Resources Congress (2018) DOI: $10.1061 / 9780784481394.006$

10. I. A. Markina, A. V. Sharkova, Journal of Applied Economic Sciences, 9(4), 687-693 (2014)

11. M. L. Kansal, V. Sridhar, N. Singh, Conference: World Environmental and Water Resources Congress (2018) DOI: 10.1061/9780784481394.004

12. A. D. Zhukov, E. Yu. Bobrova, D. B. Zelenshchikov, R. M. Mustafaev, A. O. Khimich, Advanced Materials. S. and M. Engineering, 1025-1026, 1031-1034 (2014)

13. I. Aguiló-Aguayo, L. Plaza, Innovative Technologies in Beverage Processing (2017) DOI: $10.1002 / 9781118929346$

14. S. Akçomak, Regional Studies, 53(4), 1-1 (2019) DOI: $10.1080 / 00343404.2018 .1556019$ 